\title{
Emphysema extent on computed tomography is a highly specific index in diagnosing persistent airflow limitation: a real-world study in China
}

This article was published in the following Dove Press journal: International Journal of COPD

\author{
Ting Cheng ${ }^{1-3}$ \\ Yong $\mathrm{Li}^{1,3}$ \\ Shuai Pang' \\ Huan Ying Wan ${ }^{1,3}$ \\ Guo Chao Shi ${ }^{3,4}$ \\ Qi Jian Cheng ${ }^{1,3}$ \\ Qing Yun $\mathrm{Li}^{3,4}$ \\ Zi Lai $\operatorname{Pan}^{5}$ \\ Shao Guang Huang,4 \\ 'Department of Respiratory Medicine, \\ Ruijin Hospital North, Shanghai \\ Jiao Tong University School of \\ Medicine, Shanghai, China; ${ }^{2}$ School \\ of Public Health, Fudan University, \\ Shanghai, China; ${ }^{3}$ Institute of \\ Respiratory Diseases, Shanghai Jiao \\ Tong University School of Medicine, \\ Shanghai, China; ${ }^{4}$ Department of \\ Respiratory Medicine, Ruijin Hospital, \\ Shanghai Jiao Tong University \\ School of Medicine, Shanghai, China; \\ ${ }^{5}$ Department of Radiology, Ruijin \\ Hospital North, Shanghai Jiao Tong \\ University School of Medicine, \\ Shanghai, China
}

Correspondence: Huan Ying Wan Department of Respiratory Medicine, Ruijin Hospital North, Shanghai Jiao Tong University School of Medicine, No 999, Xiwang Road, Malu Town, Jiading, Shanghai 20I80I, China

Tel +86 I $812 \quad$ I26 3363

Fax +86 02167888855

Email hy_wan2013@I63.com

Guo Chao Shi

Department of Respiratory Medicine, Ruijin Hospital, Shanghai Jiao Tong University School of Medicine, No 197, Ruijin Er Road, Huangpu District, Shanghai 200025, China

Emailshiguochao@hotmail.com
Objective: The diagnostic value of emphysema extent in consistent air flow limitation remains controversial. Therefore, we aimed to assess the value of emphysema extent on computed tomography $(\mathrm{CT})$ on the diagnosis of persistent airflow limitation. Furthermore, we developed a diagnostic criterion for further verification.

Materials and methods: We retrospectively enrolled patients who underwent chest CT and lung function test. To be specific, 671 patients were enrolled in the derivation group (Group 1.1), while 479 patients were in the internal validation group (Group 1.2). The percentage of lung volume occupied by low attenuation areas (LAA\%) and the percentile of the histogram of attenuation values were calculated.

Results: In patients with persistent airflow limitation, the LAA\% was higher and the percentile of the histogram of attenuation values was lower, compared with patients without persistent airflow limitation. Using LAA\% with a threshold of $-950 \mathrm{HU}>1.4 \%$ as the criterion, the sensitivity was $44.3 \%$ and $47.2 \%$, and the specificity was $95.2 \%$ and $95.7 \%$, in Group 1.1 and Group 1.2, respectively. The specificity was influenced by the coexistence of interstitial lung disease, pneumothorax, and post-surgery, rather than the coexistence of pneumonia, nodule, or mass. Multivariable models were also developed.

Conclusion: The emphysema extent on CT is a highly specific marker in the diagnosis of persistent airflow limitation.

Keywords: computed tomography, lung function test, emphysema, persistent airflow limitation

\section{Introduction}

COPD is characterized by persistent airflow limitation, which is usually progressive and associated with an enhanced chronic inflammatory response to noxious particles or gases. ${ }^{1}$ In the US, COPD is the fourth leading cause of morbidity and mortality, while its burden is estimated to be the fifth in 2020 worldwide. ${ }^{1,2}$ COPD is a preventable and treatable disease, and the effective treatment of COPD relies on accurate diagnosis and assessment. Thus, using different methods to facilitate the diagnosis of COPD and evaluate the severity of the disease accurately is of great significance.

According to the current diagnostic criteria of COPD, persistent airflow limitation in spirometry is indispensable. The ratio of post-bronchodilator forced expiratory volume in 1 second $\left(\mathrm{FEV}_{1}\right)$ to forced vital capacity $(\mathrm{FVC})<0.70$ confirms persistent airflow limitation. ${ }^{1}$ However, in clinical practice, some patients are not able to take the spirometry examination. Patients with dysaudia or other hearing disorders tend to get unsatisfactory spirometry results. ${ }^{3,4}$ Furthermore, patients with severe emphysema submit your manuscript

Dovepress

f in 0 
are not recommended to do spirometry for the high risk of pneumothorax. ${ }^{5}$ In addition, spirometry could detect and monitor the fluctuation of airflow limitation such as COPD exacerbation sensitively. ${ }^{6,7}$ Therefore, spirometry during COPD exacerbation may not reflect the baseline lung function accurately.

Computed tomography (CT) is widely used in the diagnosis of lung disease. It is sensitive and accurate enough to help with the diagnosis of lung infections, pneumonia, bronchiectasis, interstitial lung disease, and pleural effusion. The airflow limitation is due to several pathological structural changes in the lung, such as lung parenchyma destruction (or emphysema) and small airway disease. ${ }^{8}$ Chest CT can be used to assess the severity of emphysema correctly. ${ }^{9}$ The main index of emphysema extent on CT includes the percentage of the lung volume occupied by low attenuation areas (LAA\%) and percentile of the histogram of attenuation values (Perc n). ${ }^{10}$ Mohamed Hoesein et $\mathrm{al}^{11}$ had suggested that the emphysema extents on CT in patients with airflow limitation was significantly higher than in those without airflow limitation. Moreover, the change of emphysema extent on CT can predict mortality in COPD patients. ${ }^{12}$ In addition, Mets et al had successfully identified airflow limitation using CT images in participants in a lung cancer screening trial. ${ }^{13}$ A meta-analysis systemically analyzed the diagnostic value of CT for COPD and concluded that CT might be useful in identifying the potential suspected patients with COPD.${ }^{14}$ However, in previous studies, the sample sizes of these studies were relatively small. Besides, in the biggest study of Mets et al, bronchial dilation test was not performed and subjects were not from Asia. ${ }^{15}$

In the present study, we evaluated the efficacy of emphysema extent on CT in diagnosing persistent airflow limitation in China and tried to develop diagnostic criteria for further verification.

\section{Materials and methods}

\section{Study population}

This was a retrospective cross sectional study, which was performed in Shanghai Ruijin Hospital in China. Patients who underwent chest CT and lung function test from January 2010 to June 2014 were retrospectively enrolled in the study and divided to four groups (groups 1-4). The results of chest CT and lung function tests were recorded. The inclusion criteria of each group were as follows.

The inclusion criteria for Group 1 were 1) patients who underwent lung function test together with a bronchodilation test and 2) CT images reconstructed using a standard (or B26, B30, B31, B41, I30, I31, I41) algorithm, a section thickness of $5 \mathrm{~mm}$, and an interval of $5 \mathrm{~mm}$. Patients who had interstitial lung disease, pneumothorax, and/or post-thoracic surgery were excluded. The patients in Group 1 were further randomly divided into two groups, including a derivation group (Group 1.1) with $60 \%$ of the patients and an internal validation group (Group 1.2) with the remaining $40 \%$.

The inclusion criteria for Group 2 were 1) patients who underwent lung function test without a bronchodilation test and 2) CT images reconstructed using a standard (or B26, B30, B31, B41, I30, I31, I41) algorithm, a section thickness of $5 \mathrm{~mm}$, and an interval of $5 \mathrm{~mm}$. Patients who had interstitial lung disease, pneumothorax, and/or post-thoracic surgery were excluded.

The inclusion criteria for Group 3 were 1) patients who underwent lung function test with a bronchodilation test and 2) CT images reconstructed using other parameters (mostly a standard algorithm and a section thickness of $7.5 \mathrm{~mm}$ ). Patients who had interstitial lung disease, pneumothorax, and/or post-thoracic surgery were excluded.

The inclusion criteria for Group 4 were 1) patients who underwent lung function test with a bronchodilation test; 2) CT images reconstructed using a standard (or B26, B30, B31, B41, I30, I31, I41) algorithm, a section thickness of $5 \mathrm{~mm}$, and an interval of $5 \mathrm{~mm}$ and 3) patients who had CT manifestation of other diseases. Group 4 was further divided into seven subgroups. Group 4.1 included patients with lung infiltration on chest CT. Group 4.2 included patients with CT manifestation of bronchiectasis. Group 4.3 included patients with a lung mass on chest CT. Group 4.4 included patients with a lung nodule on chest CT. Group 4.5 included patients with interstitial lung disease reflected on CT. Group 4.6 included patients with pneumothorax, while Group 4.7 included patients who had undergone thoracic surgeries.

The present study was approved by the Ruijin North Hospital Ethics Committee.

\section{CT scanning and analysis}

Chest CT was performed according to the standardization protocols by using one of the five following CT scanners: Discovery CT750 HD (GE Medical Systems, Milwaukee, WI, USA), LightSpeed VCT (GE Medical Systems), LightSpeed16 (GE Medical Systems), Perspective (Siemens Medical Solutions, Forchheim, Germany), and SOMATOM Definition Flash (Siemens Medical Solutions). The following technical parameters were used: tube voltage, $100-140 \mathrm{kVp}$; tube current, 100-250 mA; tube rotation time, 0.8 seconds; single collimation width, $1.25 \mathrm{~mm}$; total collimation width, $20 \mathrm{~mm}$; table speed, 23 or $34 \mathrm{~mm}$ per rotation; table feed 
per rotation, 18.75 or 27.5 ; and spiral pitch factor, 0.9375 or 1.375. Images were reconstructed using a standard, bone, boneplus, lung, or B26, B30, B31, B41, B50, B70, B75, B80, I30, I31, I41, I50, I80 algorithm, a section thickness of $1.25-10 \mathrm{~mm}$, an interval similar to the section thickness, and a $512 \times 512$ matrix.

The LAA\% was calculated automatically using the commercial software Myrian ${ }^{\circledR}$ (Intrasense, Montpellier, France) under every threshold from $-1,020$ to $-201 \mathrm{HU}$ with an interval of $1 \mathrm{HU}$. Every Perc $\mathrm{n}$ was further calculated (Perc 1-Perc 99 with an interval of 1\%).

\section{Lung function test}

The lung function test (spirometry and single-breath determination of carbon monoxide uptake), including reversibility tests, was performed using Jaeger ${ }^{\circledR}$ MasterScreen Body/Diff system (CareFusion Corporation, San Diego, CA, USA) according to the American Thoracic Society/European Respiratory guidelines. The single-breath determination of carbon monoxide uptake in the lung was used to calculate the diffusing capacity and lung volume. A post-bronchodilator $\mathrm{FEV}_{1}$ to $\mathrm{FVC}$ ratio $<70 \%$ was defined as the persistent airflow limitation.

\section{Statistical analysis}

Descriptive statistics included frequency tables, median and interquartile range (for the data without normal distribution), and mean and SD (for the data with normal distribution).

The emphysema extents (LAA \% of every threshold and every percentile [Perc] of the histogram) were compared in Group 1 between patients with and without persistent airflow limitation using Mann-Whitney $U$ test.

The LAA\% using thresholds ranging from $-1,000$ to $-850 \mathrm{HU}$ with an interval of $5 \mathrm{HU}$ and Perc 1 , Perc 3 , Perc 5, Perc 6, Perc 9, Perc 12, Perc 15, Perc 18, and Perc 21 were included for the diagnostic efficiency evaluation. The areas under the receiver-operating characteristic (ROC) curve (AUCs) for LAA \% and Perc $\mathrm{n}$ were calculated in diagnosing persistent airflow limitation in Group 1.1 (derivation group). The cut points were chosen where the highest Youden index was observed, and where the specificity equaled to $90 \%, 95 \%$, and $99 \%$ in Group 1.1. The sensitivity, specificity, and positive and negative predictive values (PPV and NPV, respectively) were calculated for every cut point mentioned above using data from Group 1.1 (derivation group), Group 1.2 (internal validation group), and Groups 2, respectively. The AUC was also measured in diagnosing persistent airflow limitation in Group 1.2. The cut points were chosen as mentioned above.
Binary logistic regressions were performed to examine the factors for predicting persistent airflow limitation. Common index of emphysema extent (LAA\% [-950 HU]) and demographic characteristics of the patients (age, sex, height, and weight) were included in Model 1. Model 2 included LAA\% (-950 HU), Perc 15, and the demographic characteristics. Model 3 included LAA\% (-950 HU), LAA\% under the threshold where the AUC was the highest, Perc 15, the percentile where the AUC was the highest, and the demographic characteristics. LAA \% under every threshold, every percentile (Perc 1-Perc 99), and the demographic characteristics were included in Model 4. The AUCs for different models were calculated and the cut points were chosen as above. The sensitivity, specificity, PPV, and NPV were calculated for every cut point in Group 1.1 and Group 1.2. The ROC curve of different models and emphysema extent index were compared using $Z$ test. All statistical analyses were conducted using SPSS 17.0 (SPSS Inc., Chicago, IL, USA).

\section{Informed consent}

The present study was approved by the Ruijin North Hospital Ethics Committee, and the requirement to obtain informed written consent was waived. The reasons are as follows: 1) no foreseeable harm is expected to result from this study and less than minimal risk; 2) the waiver of informed consent will not affect the health and rights of the subjects; and 3) patient data confidentiality was protected. Statement: Informed consent was waived by the Ruijin North Hospital Ethics Committee.

\section{Results \\ Population characteristics}

A total of 2,976 patients who underwent chest CT and lung function test from January 2010 to June 2014 were enrolled. After excluding 435 patients with interstitial lung disease, pneumothorax, or post-thoracic surgery and 141 patients whose CT images were reconstructed using other parameters, 2,400 patients (CT images were reconstructed using a standard algorithm and a section thickness of $5 \mathrm{~mm}$ ) were included in Group 1 and Group 2. Among these 2,400 patients, 1,250 patients did not undergo bronchodilation tests (Group 2, the external validation group), while 1,150 patients did (Group 1). Therefore, 671 patients were randomly assigned to Group 1.1 (the derivation group) and 479 to Group 1.2 (the internal validation group). The flow chart is illustrated in Figure 1. The demographic features 


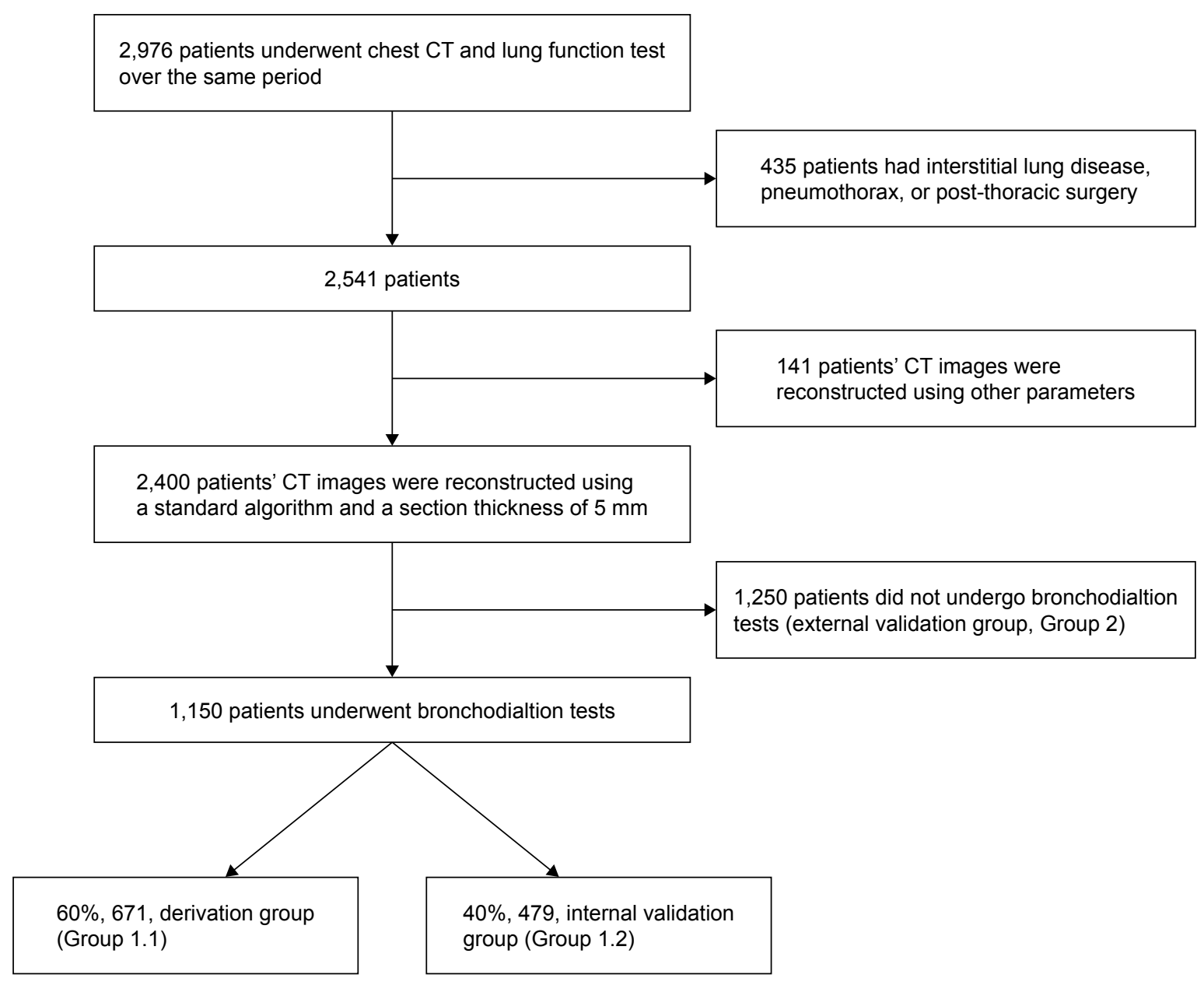

Figure I The flow chart of patient selection.

Abbreviation: CT, computed tomography.

of Group 1.1, Group 1.2, and Group 2 are summarized in Table 1. The demographic features for Group 3 and Group 4 are available in Table S1.

\section{Comparison of the emphysema extent between patients with and without persistent airflow limitation}

The emphysema extent of patients in Group 1 (including groups 1.1 and 1.2) is shown in Figure 2. The emphysema index of patients with persistent airflow limitation was significantly higher than that of those without persistent airflow limitation $(P<0.01)$. LAA\% $(-950 \mathrm{HU})$ was significantly different between patients with and without persistent airflow limitation for patients in different genders and different age groups between 40 and 90 years.

The correlation between post-bronchodilator $\mathrm{FEV}_{1}$ / FVC and emphysema extent is shown in Figure 3. Post-bronchodilator $\mathrm{FEV}_{1} / \mathrm{FVC}$ was negatively correlated with LAA $\%$ with the threshold of $-950 \mathrm{HU}$ (group 1.1: $r=-0.355$; group 1.2: $r=-0.320$ ) and positively correlated with Perc 15 (group 1.1: $r=0.306$; group 1.2: $r=0.377$ ).

\section{The diagnostic value of emphysema extent in diagnosing persistent airflow limitation}

The AUCs of different emphysema indexes in diagnosing persistent airflow limitation are shown in Figure 4. The max AUC of LAA\% was 0.83 (SD 0.02) with the threshold of $-930 \mathrm{HU}$, while the AUC with the threshold of $-950 \mathrm{HU}$ was 0.79 (SD 0.02). The max AUC of Perc $\mathrm{n}$ was 0.83 (SD 0.02) in Perc 3, while the AUC of Perc 15 was 0.78 (SD 0.02). However, no significant difference was observed in AUC between LAA\% (-930 HU) and LAA\% (-950 HU), as well as between Perc 15 and Perc 3.

The diagnostic value of emphysema extent in diagnosing persistent airflow limitation using different cut points is summarized in Part A in Table 2. Using LAA\% $(-950 \mathrm{HU})>1.4 \%$ as the criterion, the sensitivity was $44.3 \%$ 
Table I Demographic features of the derivation, internal validation, and external validation groups

\begin{tabular}{|c|c|c|c|}
\hline & Group I.I (derivation) & Group I.2 (internal validation) & Group 2 (external validation) \\
\hline Number & 671 & 479 & I,250 \\
\hline Male & $347(51.7)$ & $255(53.2)$ & $644(51.5)$ \\
\hline Age (years) & $59(50-65)$ & $59(5 I-65)$ & $61(53-69)$ \\
\hline Height (cm) & $165(160-171)$ & $165(160-17 \mid)$ & $165(|58-| 7 \mid)$ \\
\hline Weight (kg) & $63(55-7 I)$ & $65(58-72)$ & $62(55-70)$ \\
\hline BMI $\left(\mathrm{kg} / \mathrm{m}^{2}\right)$ & $23.4 \pm 3.4$ & $23.6 \pm 3.6$ & $23.2 \pm 3.4$ \\
\hline FVC (L) & $2.71(2.19-3.32)$ & $2.70(2.23-3.35)$ & $2.49(1.98-3.14)$ \\
\hline $\mathrm{FEV}_{1}(\mathrm{~L})$ & $2.18(1.63-2.70)$ & $2.11(1.6 \mathrm{I}-2.69)$ & $2.04(1.62-2.60)$ \\
\hline FEV,/FVC (\%) & $82.1(72.2-89.5)$ & $81.1(69.6-89.7)$ & $84.3(76.5-91.3)$ \\
\hline RV/TLC (\%) & $46.7 \pm 9.2$ & $47.2 \pm 9.1$ & $46.5 \pm 8.4$ \\
\hline TLC-SB & $4.60 \pm 0.99$ & $4.63 \pm 1.02$ & $4.46 \pm 0.99$ \\
\hline DLCO SB & $5.44 \pm 1.88$ & $5.46 \pm 1.89$ & $5.12 \pm 1.77$ \\
\hline DLCO/VA & $1.29(1.08-1.46)$ & $1.28(1.06-1.48)$ & $1.21(1.01-1.40)$ \\
\hline $\mathrm{FEV}, \%$ pred & $85.1(66.4-97.5)$ & $84.7(65.0-96.3)$ & $83.4(67.9-95.7)$ \\
\hline FVC\% pred & $83.4 \pm 17.5$ & $83.0 \pm 17.3$ & $80.3 \pm 17.5$ \\
\hline TLC-SB\% pred & $79.9 \pm 12.1$ & $79.9 \pm 12.3$ & $79.1 \pm 12.2$ \\
\hline DLCO SB\% pred & $67.3 \pm 17.3$ & $66.4 \pm 18.7$ & $63.0 \pm 17.5$ \\
\hline DLCO/VA\% pred & $87.8(76.2-99.2)$ & $88.7(75.1-99.5)$ & $82.0(70.7-93.4)$ \\
\hline FEV (L) post-bronchodilation & $2.31 \pm 0.86$ & $2.27 \pm 0.8 \mathrm{I}$ & NA \\
\hline FEV,/FVC (\%) post-bronchodilation & $84.1(73.9-91.0)$ & $83.2(72.0-90.2)$ & NA \\
\hline FEV,\%pred post-bronchodilation & $89.1(72.2-100.5)$ & 87.5 (70.8-99.2) & NA \\
\hline $\mathrm{FEV} / \mathrm{FVC}<70 \%$ post-bronchodilation & $131(19.5)$ & $106(22.1)$ & NA \\
\hline $\mathrm{FEV}_{1} / \mathrm{FVC}<70 \%$ & 147 (2।.9) & II 7 (24.4) & $180(14.4)$ \\
\hline Positive in bronchodilation test & $87(13)$ & $63(13.2)$ & NA \\
\hline LAA\% $(-950 \mathrm{HU})$ & $0.30(0.07-0.69)$ & $0.30(0.05-0.73)$ & $0.24(0.06-0.55)$ \\
\hline Perc I5 $(\mathrm{HU})$ & $-889(-906$ to -868$)$ & $-889(-906$ to -867$)$ & $-875(-896$ to -849$)$ \\
\hline
\end{tabular}

Abbreviations: BMI, body mass index; DLCO, diffusion capacity for carbon monoxide of the lung; FEV , forced expiratory volume in I second; FVC, forced vital capacity; LAA\%, percentage of the lung volume occupied by low attenuation areas; Perc $n$, percentile of the histogram of attenuation values; RV, residual volume; TLC, total lung capacity; TLC-SB, the single-breath diffusing capacity of the lung for CO; DLCO SB, diffusion capacity for carbon monoxide of the lung, using single-breath method; DLCO/ $\mathrm{VA}$, diffusion capacity for carbon monoxide of the lung per liters of alveolar.

and $47.2 \%$, while the specificity was $95.2 \%$ and $95.7 \%$ in Group 1.1 and Group 1.2, respectively.

In patients who did not undergo the bronchodilation test, the emphysema extent was also a highly specific index in diagnosing airflow limitation (Table 2 Part B). Using LAA\% (threshold of $-950 \mathrm{HU}$ ) $>1.4 \%$ as the criterion, the sensitivity in Group 2 was 38.3\%, while the specificity was $94.9 \%$.

On CT reconstructed by a section thickness of $7.5 \mathrm{~mm}$, the emphysema extent using the same cut point showed similar specificity and a slightly lower sensitivity in diagnosing persistent airflow limitation in Group 3 (Table 2 Part C).

\section{The diagnostic value of emphysema extent in diagnosing persistent airflow limitation in patients with other lung diseases}

The diagnostic value of emphysema extent in diagnosing persistent airflow limitation in patients with other lung diseases in Group 4 is shown in Part D in Table 2. Using LAA\% (threshold of $-950 \mathrm{HU}$ ) $>1.4 \%$ as the criterion, the specificity was still above $95 \%$ in patients with lung infiltration, as well as mass and nodule in lungs, 92.9\% in patients with bronchiectasis, and lower than $90 \%$ in patients with interstitial lung disease, pneumothorax, or post-thoracic surgery.

\section{Multivariable model based on emphysema extent for diagnosing persistent airflow limitation}

Four models were established by logistic regressions. The independent predictors of persistent airflow limitation are summarized in Table S2. The models are as follows.

Model 1: y1 $=0.792 \times$ LAA $\%(-950 \mathrm{HU})+0.026 \times$ age $($ years $)+0.608 \times \operatorname{sex}($ male $=1$, female $=0)-3.503$

Model 2: y2 $=0.68 \times$ LAA\% $(-950$ HU $)-0.017 \times$ Perc 15 $+0.029 \times$ age $($ years $)+0.023 \times$ wt $(\mathrm{kg})-20.132$

Model 3: y3 $=0.168 \times$ LAA $\%(-930 \mathrm{HU})-0.064 \times$ Perc 3 $+0.039 \times$ Perc $15+0.026 \times$ age $($ years $)-27.515$

Model 4: y4 $=0.218 \times$ Perc $4-0.554 \times$ Perc $8+0.614 \times$ Perc $33-0.321 \times$ Perc $43+0.042 \times$ Perc $97-0.304 \times$ LAA \% (-973 HU) + 0.187 × LAA \% (-927 HU) + 1.633 $\times$ LAA \% (-292 HU) -190.496

$\mathrm{P}($ persistent airflow limitation $)=\mathrm{e}^{\wedge} \mathrm{y} /\left(1+\mathrm{e}^{\wedge} \mathrm{y}\right)$ 
A
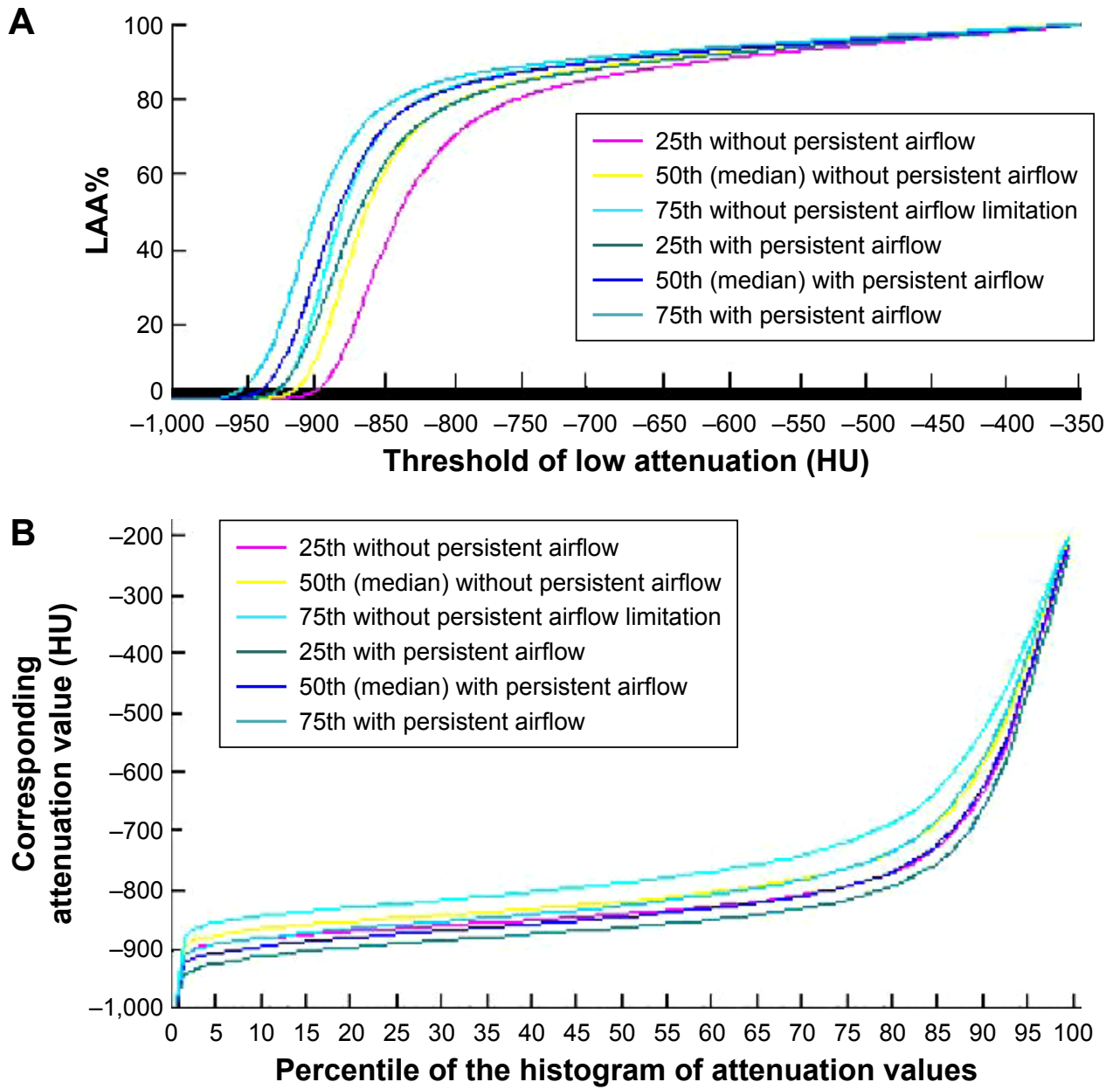

Figure 2 The emphysema extent of patients in Group I (including derivation group and internal validation group). Notes: (A) LAA\%; (B) Perc n.

Abbreviations: LAA\%, percentage of the lung volume occupied by low attenuation areas; Perc $n$, percentile of the histogram of attenuation values.

A

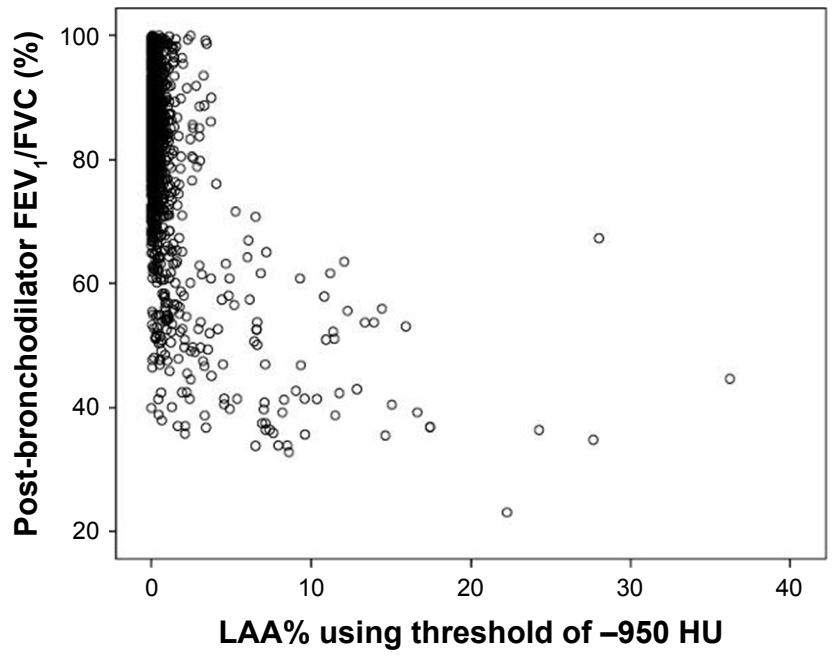

B

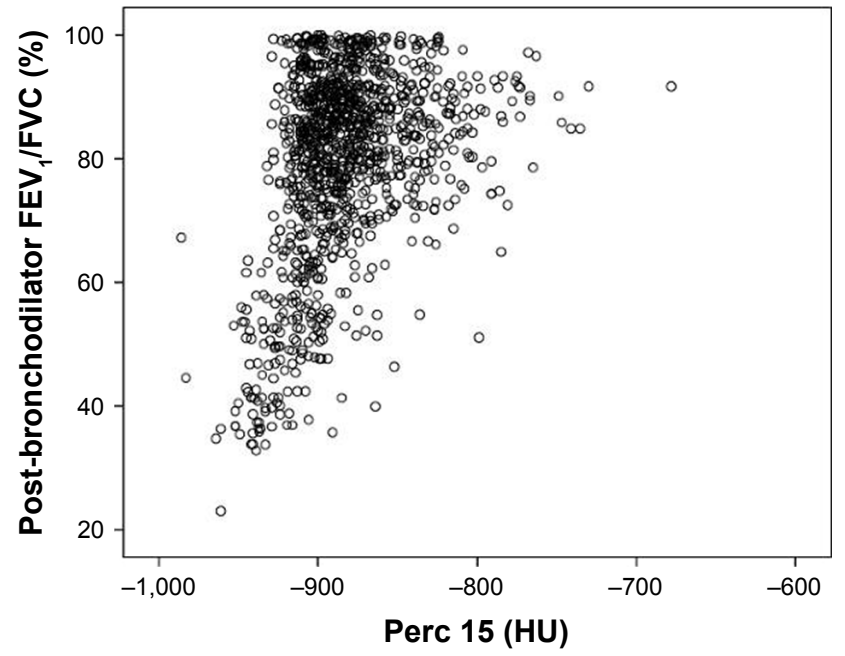

Figure 3 The correlation between post-bronchodilator FEV,/FVC and emphysema extent. Notes: (A) LAA\% using the threshold of $-950 \mathrm{HU}$; (B) Perc 15 (HU).

Abbreviations: $\mathrm{FEV}_{1}$, forced expiratory volume in I second; FVC, forced vital capacity; LAA\%, percentage of the lung volume occupied by low attenuation areas; Perc $\mathrm{n}$, percentile of the histogram of attenuation values. 

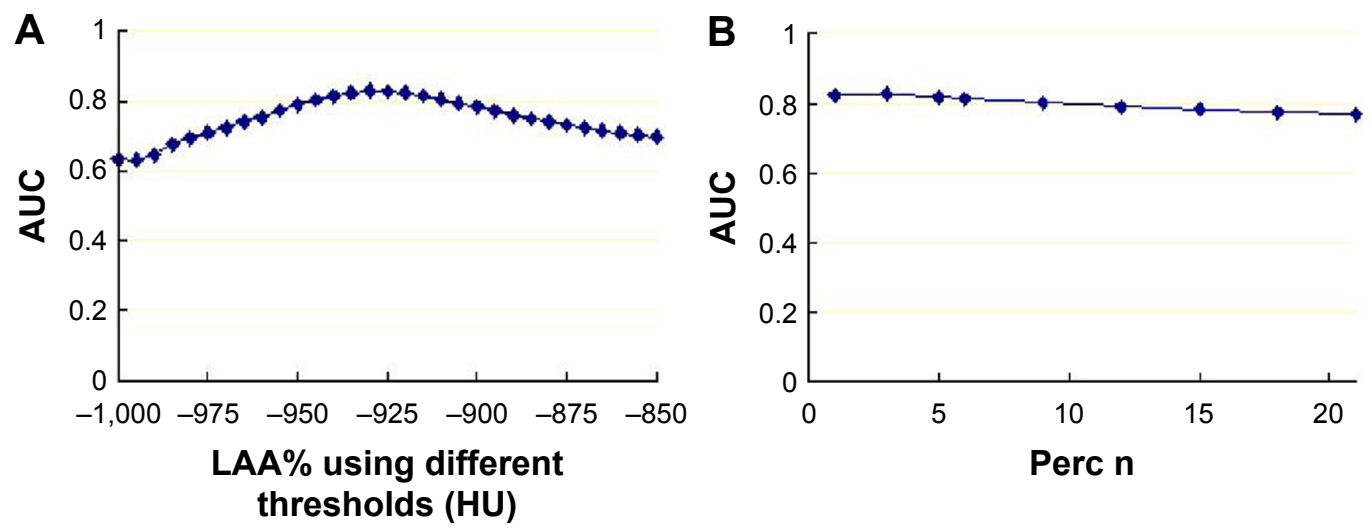

Figure 4 The AUCs of different emphysema indexes in diagnosing persistent airflow limitation.

Notes: (A) LAA\% using different thresholds (HU); (B) Perc $n$.

Abbreviations: AUC, area under the ROC curve; LAA\%, percentage of the lung volume occupied by low attenuation areas; Perc n, percentile of the histogram of attenuation values; ROC, receiver-operating characteristic.

Table 2 Diagnostic values of the emphysema extent in diagnosing persistent airflow limitation using different cut point in groups I-4

\begin{tabular}{|c|c|c|c|c|c|c|c|c|c|}
\hline Rule & $\mathbf{A}$ & B & $\mathbf{C}$ & D & Sensitivity (\%) & Specificity (\%) & PPV (\%) & NPV (\%) & Kappa \\
\hline \multicolumn{10}{|l|}{ A: Group I } \\
\hline \multicolumn{10}{|c|}{ LAA\% $(-950 \mathrm{HU})>0.84 \%$} \\
\hline Group I.I & 77 & 63 & 54 & 477 & 58.8 & 88.3 & 55.0 & 89.8 & 0.83 \\
\hline Group I.2 & 65 & 45 & 41 & 328 & 61.3 & 87.9 & 59.1 & 88.9 & 0.82 \\
\hline \multicolumn{10}{|c|}{ LAA\% $(-950 \mathrm{HU})>0.90 \%$} \\
\hline Group I.I & 73 & 53 & 58 & 487 & 55.7 & 90.2 & 57.9 & 89.4 & 0.83 \\
\hline Group 1.2 & 62 & 39 & 44 & 334 & 58.5 & 89.5 & 61.4 & 88.4 & 0.83 \\
\hline \multicolumn{10}{|c|}{ LAA\% $(-950 \mathrm{HU})>1.4 \%$} \\
\hline Group I.I & 58 & 26 & 73 & 514 & 44.3 & 95.2 & 69.0 & 87.6 & 0.85 \\
\hline Group 1.2 & 50 & 16 & 56 & 357 & 47.2 & 95.7 & 75.8 & 86.4 & 0.85 \\
\hline \multicolumn{10}{|c|}{ LAA\% $(-950 \mathrm{HU})>3.0 \%$} \\
\hline Group I.I & 43 & 5 & 88 & 535 & 32.8 & 99.1 & 89.6 & 85.9 & 0.86 \\
\hline Group 1.2 & 33 & 4 & 73 & 369 & 31.1 & 98.9 & 89.2 & 83.5 & 0.84 \\
\hline \multicolumn{10}{|c|}{ Perc I5 <-907 HU } \\
\hline Group I.I & 73 & 76 & 58 & 464 & 55.7 & 85.9 & 49.0 & 88.9 & 0.8 \\
\hline Group 1.2 & 63 & 52 & 43 & 321 & 59.4 & 86.1 & 54.8 & 88.2 & 0.8 \\
\hline \multicolumn{10}{|c|}{ Perc $15<-910 \mathrm{HU}$} \\
\hline Group I.I & 63 & 53 & 68 & 487 & 48.1 & 90.2 & 54.3 & 87.7 & 0.82 \\
\hline Group 1.2 & 60 & 32 & 46 & 341 & 56.6 & 91.4 & 65.2 & 88.1 & 0.84 \\
\hline \multicolumn{10}{|c|}{ Perc I5 <-9I5 HU } \\
\hline Group I.I & 54 & 23 & 77 & 517 & 41.2 & 95.7 & 70.1 & 87.0 & 0.85 \\
\hline Group 1.2 & 49 & 19 & 57 & 354 & 46.2 & 94.9 & 72.1 & 86.1 & 0.84 \\
\hline \multicolumn{10}{|c|}{ Perc I5 $<-928 \mathrm{HU}$} \\
\hline Group I.I & 33 & 4 & 98 & 536 & 25.2 & 99.3 & 89.2 & 84.5 & 0.85 \\
\hline Group I.2 & 24 & 0 & 82 & 373 & 22.6 & 100.0 & 100.0 & 82.0 & 0.83 \\
\hline \multicolumn{10}{|c|}{ LAA\% $(-930 \mathrm{HU})>1.4 \%$} \\
\hline Group I.I & 103 & 142 & 28 & 398 & 78.6 & 73.7 & 42.0 & 93.4 & 0.75 \\
\hline Group I.2 & 86 & 97 & 20 & 276 & $8 I .1$ & 74.0 & 47.0 & 93.2 & 0.76 \\
\hline \multicolumn{10}{|c|}{ LAA\% $(-930 \mathrm{HU})>3.4 \%$} \\
\hline Group I.I & 76 & 53 & 55 & 487 & 58.0 & 90.2 & 58.9 & 89.9 & 0.84 \\
\hline Group I.2 & 72 & 34 & 34 & 339 & 67.9 & 90.9 & 67.9 & 90.9 & 0.86 \\
\hline \multicolumn{10}{|c|}{ LAA\% $(-930 \mathrm{HU})>5.2 \%$} \\
\hline Group I.I & 65 & 26 & 66 & 514 & 49.6 & 95.2 & 7I. 4 & 88.6 & 0.86 \\
\hline Group I.2 & 56 & 20 & 50 & 353 & 52.8 & 94.6 & 73.7 & 87.6 & 0.85 \\
\hline \multicolumn{10}{|c|}{ LAA\% $(-930 \mathrm{HU})>13 \%$} \\
\hline Group I.I & 38 & 5 & 93 & 535 & 29.0 & 99.1 & 88.4 & 85.2 & 0.85 \\
\hline Group 1.2 & 25 & 1 & 81 & 372 & 23.6 & 99.7 & 96.2 & 82.1 & 0.83 \\
\hline
\end{tabular}


Table 2 (Continued)

\begin{tabular}{|c|c|c|c|c|c|c|c|c|c|}
\hline Rule & $\mathbf{A}$ & B & C & D & Sensitivity (\%) & Specificity (\%) & PPV (\%) & NPV (\%) & Kappa \\
\hline \multicolumn{10}{|l|}{ Perc $3<-922 \mathrm{HU}$} \\
\hline Group I.I & 96 & 124 & 35 & 416 & 73.3 & 77.0 & 43.6 & 92.2 & 0.76 \\
\hline Group 1.2 & 85 & 78 & 21 & 295 & 80.2 & 79.1 & 52.1 & 93.4 & 0.79 \\
\hline \multicolumn{10}{|l|}{ Perc $3<-93$ I HU } \\
\hline Group I.I & 75 & 52 & 56 & 488 & 57.3 & 90.4 & 59.1 & 89.7 & 0.84 \\
\hline Group I.2 & 70 & 32 & 36 & 341 & 66.0 & 91.4 & 68.6 & 90.5 & 0.86 \\
\hline \multicolumn{10}{|l|}{ Perc $3<-937 \mathrm{HU}$} \\
\hline Group I.I & 64 & 24 & 67 & 516 & 48.9 & 95.6 & 72.7 & 88.5 & 0.86 \\
\hline Group I.2 & 54 & 16 & 52 & 357 & 50.9 & 95.7 & 77.1 & 87.3 & 0.86 \\
\hline \multicolumn{10}{|l|}{ Perc $3<-95$ I HU } \\
\hline Group I.I & 39 & 4 & 92 & 536 & 29.8 & 99.3 & 90.7 & 85.4 & 0.86 \\
\hline Group 1.2 & 28 & 4 & 78 & 369 & 26.4 & 98.9 & 87.5 & 82.6 & 0.83 \\
\hline \multicolumn{10}{|l|}{ B: Group 2} \\
\hline LAA\% $(-950 \mathrm{HU})>0.84 \%$ & 86 & 113 & 94 & 957 & 47.8 & 89.4 & 43.2 & 91.1 & 0.83 \\
\hline LAA\% $(-950 \mathrm{HU})>0.90 \%$ & 83 & 99 & 97 & 971 & 46.1 & 90.7 & 45.6 & 90.9 & 0.84 \\
\hline LAA\% $(-950 \mathrm{HU})>1.4 \%$ & 69 & 55 & 111 & 1,015 & 38.3 & 94.9 & 55.6 & 90.1 & 0.87 \\
\hline LAA\% $(-950 \mathrm{HU})>3.0 \%$ & 44 & 11 & 136 & 1,059 & 24.4 & 99.0 & 80.0 & 88.6 & 0.88 \\
\hline Perc I5 <-907 HU & 77 & 84 & 103 & 986 & 42.8 & 92.1 & 47.8 & 90.5 & 0.85 \\
\hline Perc $15<-910 \mathrm{HU}$ & 73 & 61 & 107 & 1,009 & 40.6 & 94.3 & 54.5 & 90.4 & 0.87 \\
\hline Perc I5 <-915 HU & 64 & 37 & 116 & 1,033 & 35.6 & 96.5 & 63.4 & 89.9 & 0.88 \\
\hline Perc I5 $<-928 \mathrm{HU}$ & 35 & 4 & 145 & 1,066 & 19.4 & 99.6 & 89.7 & 88.0 & 0.88 \\
\hline LAA\% $(-930 \mathrm{HU})>1.4 \%$ & 112 & 215 & 68 & 855 & 62.2 & 79.9 & 34.3 & 92.6 & 0.77 \\
\hline LAA\% $(-930 \mathrm{HU})>3.4 \%$ & 86 & 77 & 94 & 993 & 47.8 & 92.8 & 52.8 & 91.4 & 0.86 \\
\hline LAA\% $(-930 \mathrm{HU})>5.2 \%$ & 75 & 40 & 105 & 1,030 & 41.7 & 96.3 & 65.2 & 90.7 & 0.88 \\
\hline LAA\% $(-930 \mathrm{HU})>13 \%$ & 39 & 5 & $|4|$ & 1,065 & 21.7 & 99.5 & 88.6 & 88.3 & 0.88 \\
\hline Perc $3<-922 \mathrm{HU}$ & 108 & 165 & 72 & 905 & 60.0 & 84.6 & 39.6 & 92.6 & 0.81 \\
\hline Perc $3<-93$ I HU & 85 & 72 & 95 & 998 & 47.2 & 93.3 & 54.1 & 91.3 & 0.87 \\
\hline Perc $3<-937 \mathrm{HU}$ & 70 & 38 & 110 & 1,032 & 38.9 & 96.4 & 64.8 & 90.4 & 0.88 \\
\hline Perc $3<-95$ I HU & 44 & 10 & 136 & 1,060 & 24.4 & 99.1 & 81.5 & 88.6 & 0.88 \\
\hline \multicolumn{10}{|l|}{ C: Group 3} \\
\hline LAA\% $(-950 \mathrm{HU})>0.84 \%$ & 2 & 3 & 3 & 32 & 40.0 & 91.4 & 40.0 & 91.4 & 0.85 \\
\hline LAA\% $(-950 \mathrm{HU})>0.90 \%$ & 2 & 3 & 3 & 32 & 40.0 & 91.4 & 40.0 & 91.4 & 0.85 \\
\hline LAA\% $(-950 \mathrm{HU})>1.4 \%$ & 2 & 2 & 3 & 33 & 40.0 & 94.3 & 50.0 & 91.7 & 0.88 \\
\hline LAA\% $(-950 \mathrm{HU})>3.0 \%$ & 1 & 0 & 4 & 35 & 20.0 & 100.0 & 100.0 & 89.7 & 0.90 \\
\hline Perc I5 <-907 HU & 2 & 1 & 3 & 34 & 40.0 & 97.1 & 66.7 & 91.9 & 0.90 \\
\hline Perc I5 <-910 HU & 2 & I & 3 & 34 & 40.0 & 97.1 & 66.7 & 91.9 & 0.90 \\
\hline Perc I5 <-915 HU & 2 & 0 & 3 & 35 & 40.0 & 100.0 & 100.0 & 92.1 & 0.93 \\
\hline Perc I5 $<-928 \mathrm{HU}$ & 0 & 0 & 5 & 35 & 0.0 & 100.0 & NA & 87.5 & 0.88 \\
\hline LAA\% $(-930 \mathrm{HU})>1.4 \%$ & 2 & 6 & 3 & 29 & 40.0 & 82.9 & 25.0 & 90.6 & 0.78 \\
\hline LAA\% $(-930 \mathrm{HU})>3.4 \%$ & 2 & 2 & 3 & 33 & 40.0 & 94.3 & 50.0 & 91.7 & 0.88 \\
\hline LAA\% $(-930 \mathrm{HU})>5.2 \%$ & 2 & I & 3 & 34 & 40.0 & 97.1 & 66.7 & 91.9 & 0.90 \\
\hline LAA\% $(-930 \mathrm{HU})>13 \%$ & 0 & 0 & 5 & 35 & 0.0 & 100.0 & NA & 87.5 & 0.88 \\
\hline Perc $3<-922 \mathrm{HU}$ & 2 & 4 & 3 & 31 & 40.0 & 88.6 & 33.3 & 91.2 & 0.83 \\
\hline Perc $3<-931 \mathrm{HU}$ & 2 & 2 & 3 & 33 & 40.0 & 94.3 & 50.0 & 91.7 & 0.88 \\
\hline Perc $3<-937 \mathrm{HU}$ & 2 & I & 3 & 34 & 40.0 & 97.1 & 66.7 & 91.9 & 0.90 \\
\hline Perc $3<-95$ I HU & 1 & 0 & 4 & 35 & 20.0 & 100.0 & 100.0 & 89.7 & 0.90 \\
\hline \multicolumn{10}{|l|}{ D: Group 4} \\
\hline \multicolumn{10}{|l|}{ LAA\% $(-950 \mathrm{HU})>0.84 \%$} \\
\hline With lung infiltration & 48 & 38 & 40 & 233 & 54.5 & 86.0 & 55.8 & 85.3 & 0.78 \\
\hline With bronchiectasis & 19 & 8 & 7 & 34 & 73.1 & 81.0 & 70.4 & 82.9 & 0.78 \\
\hline With mass in lung & 11 & 10 & 4 & 52 & 73.3 & 83.9 & 52.4 & 92.9 & 0.82 \\
\hline With nodule in lung & 78 & 56 & 55 & 470 & 58.6 & 89.4 & 58.2 & 89.5 & 0.83 \\
\hline With interstitial lung disease & 18 & 14 & 4 & 49 & 81.8 & 77.8 & 56.3 & 92.5 & 0.79 \\
\hline With pneumothorax & 1 & 1 & 0 & 5 & 100 & 83.3 & 50.0 & 100 & 0.86 \\
\hline Post-thoracic surgery & 1 & 7 & 5 & 21 & 16.7 & 75.0 & 12.5 & 80.8 & 0.65 \\
\hline
\end{tabular}


Table 2 (Continued)

\begin{tabular}{|c|c|c|c|c|c|c|c|c|c|}
\hline Rule & A & B & C & D & Sensitivity (\%) & Specificity (\%) & PPV (\%) & NPV (\%) & Kappa \\
\hline \multicolumn{10}{|l|}{ LAA\% $(-950 \mathrm{HU})>0.90 \%$} \\
\hline With lung infiltration & 45 & 32 & 43 & 239 & 51.1 & 88.2 & 58.4 & 84.8 & 0.79 \\
\hline With bronchiectasis & 19 & 8 & 7 & 34 & 73.1 & 81.0 & 70.4 & 82.9 & 0.78 \\
\hline With mass in lung & 10 & 7 & 5 & 55 & 66.7 & 88.7 & 58.8 & 91.7 & 0.84 \\
\hline With nodule in lung & 76 & 47 & 57 & 479 & 57.1 & 91.1 & 61.8 & 89.4 & 0.84 \\
\hline With interstitial lung disease & 17 & 12 & 5 & 51 & 77.3 & 81.0 & 58.6 & 91.1 & 0.80 \\
\hline With pneumothorax & 1 & 1 & 0 & 5 & 100 & 83.3 & 50.0 & 100 & 0.86 \\
\hline Post-thoracic surgery & 1 & 6 & 5 & 22 & 16.7 & 78.6 & 14.3 & 81.5 & 0.68 \\
\hline \multicolumn{10}{|l|}{ LAA\% $(-950 \mathrm{HU})>1.4 \%$} \\
\hline With lung infiltration & 33 & 9 & 55 & 262 & 37.5 & 96.7 & 78.6 & 82.6 & 0.82 \\
\hline With bronchiectasis & 14 & 3 & 12 & 39 & 53.8 & 92.9 & 82.4 & 76.5 & 0.78 \\
\hline With mass in lung & 8 & 2 & 7 & 60 & 53.3 & 96.8 & 80.0 & 89.6 & 0.88 \\
\hline With nodule in lung & 65 & 24 & 68 & 502 & 48.9 & 95.4 & 73.0 & 88.1 & 0.86 \\
\hline With interstitial lung disease & 17 & 9 & 5 & 54 & 77.3 & 85.7 & 65.4 & 91.5 & 0.84 \\
\hline With pneumothorax & 1 & 1 & 0 & 5 & 100 & 83.3 & 50.0 & 100 & 0.86 \\
\hline Post-thoracic surgery & 0 & 4 & 6 & 24 & 0.0 & 85.7 & 0.0 & 80.0 & $0.7 \mathrm{I}$ \\
\hline \multicolumn{10}{|l|}{ LAA\% $(-950 \mathrm{HU})>3.0 \%$} \\
\hline With lung infiltration & 22 & 2 & 66 & 269 & 25.0 & 99.3 & 91.7 & 80.3 & 0.81 \\
\hline With bronchiectasis & 10 & I & 16 & 41 & 38.5 & 97.6 & 90.9 & 71.9 & 0.75 \\
\hline With mass in lung & 5 & 0 & 10 & 62 & 33.3 & 100 & 100 & 86.1 & 0.87 \\
\hline With nodule in lung & 40 & 5 & 93 & 521 & 30.1 & 99.0 & 88.9 & 84.9 & 0.85 \\
\hline With interstitial lung disease & 16 & 4 & 6 & 59 & 72.7 & 93.7 & 80.0 & 90.8 & 0.88 \\
\hline With pneumothorax & 0 & 0 & $\mathrm{I}$ & 6 & 0.0 & 100 & NA & 85.7 & 0.86 \\
\hline Post-thoracic surgery & 0 & 3 & 6 & 25 & 0.0 & 89.3 & 0.0 & 80.6 & 0.74 \\
\hline \multicolumn{10}{|l|}{ Perc I5 <-907 HU } \\
\hline With lung infiltration & 43 & 40 & 45 & 231 & 48.9 & 85.2 & 51.8 & 83.7 & 0.76 \\
\hline With bronchiectasis & 17 & 9 & 9 & 33 & 65.4 & 78.6 & 65.4 & 78.6 & 0.74 \\
\hline With mass in lung & 7 & 5 & 8 & 57 & 46.7 & 91.9 & 58.3 & 87.7 & 0.83 \\
\hline With nodule in lung & 79 & 68 & 54 & 458 & 59.4 & 87.1 & 53.7 & 89.5 & 0.81 \\
\hline With interstitial lung disease & 14 & 5 & 8 & 58 & 63.6 & 92.1 & 73.7 & 87.9 & 0.85 \\
\hline With pneumothorax & 0 & 2 & $\mathrm{I}$ & 4 & 0.0 & 66.7 & 0.0 & 80.0 & 0.57 \\
\hline Post-thoracic surgery & 0 & 3 & 6 & 25 & 0.0 & 89.3 & 0.0 & 80.6 & 0.74 \\
\hline \multicolumn{10}{|l|}{ Perc I5 <-910 HU } \\
\hline With lung infiltration & 37 & 25 & 51 & 246 & 42.0 & 90.8 & 59.7 & 82.8 & 0.79 \\
\hline With bronchiectasis & 15 & 4 & 11 & 38 & 57.7 & 90.5 & 78.9 & 77.6 & 0.78 \\
\hline With mass in lung & 6 & 1 & 9 & 61 & 40.0 & 98.4 & 85.7 & 87.1 & 0.87 \\
\hline With nodule in lung & 71 & 49 & 62 & 477 & 53.4 & 90.7 & 59.2 & 88.5 & 0.83 \\
\hline With interstitial lung disease & 14 & 4 & 8 & 59 & 63.6 & 93.7 & 77.8 & 88.1 & 0.86 \\
\hline With pneumothorax & 0 & 0 & $\mathrm{I}$ & 6 & 0.0 & 100 & NA & 85.7 & 0.86 \\
\hline Post-thoracic surgery & 0 & 3 & 6 & 25 & 0.0 & 89.3 & 0.0 & 80.6 & 0.74 \\
\hline \multicolumn{10}{|l|}{ Perc I5 <-915 HU } \\
\hline With lung infiltration & 28 & 16 & 60 & 255 & 31.8 & 94.1 & 63.6 & 81.0 & 0.79 \\
\hline With bronchiectasis & 12 & 2 & 14 & 40 & 46.2 & 95.2 & 85.7 & 74.1 & 0.76 \\
\hline With mass in lung & 6 & I & 9 & 61 & 40.0 & 98.4 & 85.7 & 87.1 & 0.87 \\
\hline With nodule in lung & 55 & 22 & 78 & 504 & 41.4 & 95.8 & 71.4 & 86.6 & 0.85 \\
\hline With interstitial lung disease & 14 & 2 & 8 & 61 & 63.6 & 96.8 & 87.5 & 88.4 & 0.88 \\
\hline With pneumothorax & 0 & 0 & $\mathrm{I}$ & 6 & 0.0 & 100 & NA & 85.7 & 0.86 \\
\hline Post-thoracic surgery & 0 & 2 & 6 & 26 & 0.0 & 92.9 & 0.0 & 81.3 & 0.76 \\
\hline \multicolumn{10}{|l|}{ Perc $15<-928 \mathrm{HU}$} \\
\hline With lung infiltration & 19 & I & 69 & 270 & 21.6 & 99.6 & 95.0 & 79.6 & 0.81 \\
\hline With bronchiectasis & 8 & 1 & 18 & 41 & 30.8 & 97.6 & 88.9 & 69.5 & 0.72 \\
\hline With mass in lung & 5 & 0 & 10 & 62 & 33.3 & 100 & 100 & 86.1 & 0.87 \\
\hline With nodule in lung & 34 & 5 & 99 & 521 & 25.6 & 99.0 & 87.2 & 84.0 & 0.84 \\
\hline With interstitial lung disease & 15 & 4 & 7 & 59 & 68.2 & 93.7 & 78.9 & 89.4 & 0.87 \\
\hline With pneumothorax & 0 & 0 & 1 & 6 & 0.0 & 100 & NA & 85.7 & 0.86 \\
\hline Post-thoracic surgery & 0 & 3 & 6 & 25 & 0.0 & 89.3 & 0.0 & 80.6 & 0.74 \\
\hline
\end{tabular}


Table 2 (Continued)

\begin{tabular}{|c|c|c|c|c|c|c|c|c|c|}
\hline Rule & $\mathbf{A}$ & B & C & D & Sensitivity (\%) & Specificity (\%) & PPV (\%) & NPV (\%) & Kappa \\
\hline \multicolumn{10}{|l|}{ LAA\% $(-930 \mathrm{HU})>1.4 \%$} \\
\hline With lung infiltration & 64 & 78 & 24 & 193 & 72.7 & 71.2 & 45.1 & 88.9 & 0.72 \\
\hline With bronchiectasis & 23 & 17 & 3 & 25 & 88.5 & 59.5 & 57.5 & 89.3 & 0.71 \\
\hline With mass in lung & 11 & 15 & 4 & 47 & 73.3 & 75.8 & 42.3 & 92.2 & 0.75 \\
\hline With nodule in lung & 109 & 132 & 24 & 394 & 82.0 & 74.9 & 45.2 & 94.3 & 0.76 \\
\hline With interstitial lung disease & 18 & 18 & 4 & 45 & 81.8 & 71.4 & 50.0 & 91.8 & 0.74 \\
\hline With pneumothorax & I & 2 & 0 & 4 & 100 & 66.7 & 33.3 & 100 & 0.71 \\
\hline Post-thoracic surgery & 2 & 7 & 4 & 21 & 33.3 & 75.0 & 22.2 & 84.0 & 0.68 \\
\hline \multicolumn{10}{|l|}{ LAA\% $(-930 \mathrm{HU})>3.4 \%$} \\
\hline With lung infiltration & 49 & 28 & 39 & 243 & 55.7 & 89.7 & 63.6 & 86.2 & 0.81 \\
\hline With bronchiectasis & 17 & 8 & 9 & 34 & 65.4 & 81.0 & 68.0 & 79.1 & 0.75 \\
\hline With mass in lung & 10 & 4 & 5 & 58 & 66.7 & 93.5 & 71.4 & 92.1 & 0.88 \\
\hline With nodule in lung & 85 & 53 & 48 & 473 & 63.9 & 89.9 & 61.6 & 90.8 & 0.85 \\
\hline With interstitial lung disease & 17 & 11 & 5 & 52 & 77.3 & 82.5 & 60.7 & 91.2 & 0.81 \\
\hline With pneumothorax & 1 & 1 & 0 & 5 & 100 & 83.3 & 50.0 & 100 & 0.86 \\
\hline Post-thoracic surgery & I & 6 & 5 & 22 & 16.7 & 78.6 & 14.3 & 81.5 & 0.68 \\
\hline \multicolumn{10}{|l|}{ LAA\% $(-930 \mathrm{HU})>5.2 \%$} \\
\hline With lung infiltration & 38 & 17 & 50 & 254 & 43.2 & 93.7 & 69.1 & 83.6 & 0.81 \\
\hline With bronchiectasis & 16 & 4 & 10 & 38 & 61.5 & 90.5 & 80.0 & 79.2 & 0.79 \\
\hline With mass in lung & 6 & I & 9 & 61 & 40.0 & 98.4 & 85.7 & 87.1 & 0.87 \\
\hline With nodule in lung & 71 & 24 & 62 & 502 & 53.4 & 95.4 & 74.7 & 89.0 & 0.87 \\
\hline With interstitial lung disease & 16 & 5 & 6 & 58 & 72.7 & 92.1 & 76.2 & 90.6 & 0.87 \\
\hline With pneumothorax & 0 & 0 & 1 & 6 & 0.0 & 100 & NA & 85.7 & 0.86 \\
\hline Post-thoracic surgery & 0 & 3 & 6 & 25 & 0.0 & 89.3 & 0.0 & 80.6 & 0.74 \\
\hline \multicolumn{10}{|l|}{ LAA\% $(-930 \mathrm{HU})>13 \%$} \\
\hline With lung infiltration & 19 & I & 69 & 270 & 21.6 & 99.6 & 95.0 & 79.6 & 0.81 \\
\hline With bronchiectasis & 9 & 0 & 17 & 42 & 34.6 & 100 & 100 & 71.2 & 0.75 \\
\hline With mass in lung & 5 & I & 10 & 61 & 33.3 & 98.4 & 83.3 & 85.9 & 0.86 \\
\hline With nodule in lung & 35 & 3 & 98 & 523 & 26.3 & 99.4 & 92.1 & 84.2 & 0.85 \\
\hline With interstitial lung disease & 10 & I & 12 & 62 & 45.5 & 98.4 & 90.9 & 83.8 & 0.85 \\
\hline With pneumothorax & 0 & 0 & 1 & 6 & 0.0 & 100 & NA & 85.7 & 0.86 \\
\hline Post-thoracic surgery & 0 & I & 6 & 27 & 0.0 & 96.4 & 0.0 & 81.8 & 0.79 \\
\hline \multicolumn{10}{|l|}{ Perc $3<-922 \mathrm{HU}$} \\
\hline With lung infiltration & 60 & 59 & 28 & 212 & 68.2 & 78.2 & 50.4 & 88.3 & 0.76 \\
\hline With bronchiectasis & 21 & 15 & 5 & 27 & 80.8 & 64.3 & 58.3 & 84.4 & 0.71 \\
\hline With mass in lung & 11 & 12 & 4 & 50 & 73.3 & 80.6 & 47.8 & 92.6 & 0.79 \\
\hline With nodule in lung & 103 & 114 & 30 & 412 & 77.4 & 78.3 & 47.5 & 93.2 & 0.78 \\
\hline With interstitial lung disease & 17 & 16 & 5 & 47 & 77.3 & 74.6 & 51.5 & 90.4 & 0.75 \\
\hline With pneumothorax & 1 & 2 & 0 & 4 & 100 & 66.7 & 33.3 & 100 & $0.7 \mathrm{I}$ \\
\hline Post-thoracic surgery & 1 & 8 & 5 & 20 & 16.7 & 71.4 & II.I & 80.0 & 0.62 \\
\hline \multicolumn{10}{|l|}{ Perc $3<-93$ I HU } \\
\hline With lung infiltration & 47 & 28 & 41 & 243 & 53.4 & 89.7 & 62.7 & 85.6 & 0.81 \\
\hline With bronchiectasis & 17 & 8 & 9 & 34 & 65.4 & 81.0 & 68.0 & 79.1 & 0.75 \\
\hline With mass in lung & 10 & 3 & 5 & 59 & 66.7 & 95.2 & 76.9 & 92.2 & 0.90 \\
\hline With nodule in lung & 82 & 51 & 51 & 475 & 61.7 & 90.3 & 61.7 & 90.3 & 0.85 \\
\hline With interstitial lung disease & 17 & 10 & 5 & 53 & 77.3 & 84.1 & 63.0 & 91.4 & 0.82 \\
\hline With pneumothorax & 1 & 1 & 0 & 5 & 100 & 83.3 & 50.0 & 100 & 0.86 \\
\hline Post-thoracic surgery & I & 5 & 5 & 23 & 16.7 & 82.1 & 16.7 & 82.1 & 0.71 \\
\hline \multicolumn{10}{|l|}{ Perc $3<-937 \mathrm{HU}$} \\
\hline With lung infiltration & 18 & 0 & 70 & 271 & 20.5 & 100 & 100 & 79.5 & 0.81 \\
\hline With bronchiectasis & 9 & 0 & 17 & 42 & 34.6 & 100 & 100 & 71.2 & 0.75 \\
\hline With mass in lung & 4 & 0 & 11 & 62 & 26.7 & 100 & 100 & 84.9 & 0.86 \\
\hline With nodule in lung & 32 & 2 & 101 & 524 & 24.1 & 99.6 & 94.1 & 83.8 & 0.84 \\
\hline With interstitial lung disease & 10 & I & 12 & 62 & 45.5 & 98.4 & 90.9 & 83.8 & 0.85 \\
\hline With pneumothorax & 0 & 0 & 1 & 6 & 0.0 & 100 & NA & 85.7 & 0.86 \\
\hline Post-thoracic surgery & 0 & I & 6 & 27 & 0.0 & 96.4 & 0.0 & 81.8 & 0.79 \\
\hline
\end{tabular}


Table 2 (Continued)

\begin{tabular}{|c|c|c|c|c|c|c|c|c|c|}
\hline Rule & A & B & C & D & Sensitivity (\%) & Specificity (\%) & PPV (\%) & NPV (\%) & Kappa \\
\hline \multicolumn{10}{|l|}{ Perc $3<-95$ I HU } \\
\hline With lung infiltration & 38 & 15 & 50 & 256 & 43.2 & 94.5 & 71.7 & 83.7 & 0.82 \\
\hline With bronchiectasis & 16 & 4 & 10 & 38 & 61.5 & 90.5 & 80.0 & 79.2 & 0.79 \\
\hline With mass in lung & 7 & 1 & 8 & 61 & 46.7 & 98.4 & 87.5 & 88.4 & 0.88 \\
\hline With nodule in lung & 72 & 25 & 61 & 501 & 54.1 & 95.2 & 74.2 & 89.1 & 0.87 \\
\hline With interstitial lung disease & 17 & 5 & 5 & 58 & 77.3 & 92.1 & 77.3 & 92.1 & 0.88 \\
\hline With pneumothorax & 0 & 0 & 1 & 6 & 0.0 & 100 & NA & 85.7 & 0.86 \\
\hline Post-thoracic surgery & 0 & 3 & 6 & 25 & 0.0 & 89.3 & 0.0 & 80.6 & 0.74 \\
\hline
\end{tabular}

Notes: A, true positives (with obvious emphysema and persistent airflow limitation); B, false positives (with obvious emphysema, but without persistent airflow limitation); C, false negatives (without obvious emphysema, but with persistent airflow limitation); D, true negatives (without obvious emphysema and persistent airflow limitation). Abbreviations: LAA\%, percentage of the lung volume occupied by low attenuation areas; NPV, negative predictive value; Perc n, percentile of the histogram of attenuation values; PPV, positive predictive value.

Model 4 showed the best discrimination in both Group 1.1 and Group 1.2. The discrimination in Group 1.1 was Model 4> Model 3 $>$ LAA\% $(-930 \mathrm{HU})>$ Perc $3>$ Model $2>$ Model 1 $>$ LAA \% $(-950 \mathrm{HU})>$ Perc 15. In Group 1.2, it was Model 4>Model $3>$ Model $2>$ Perc 3 $>$ LAA\% $(-930$ HU) $>$ Model $1>$ Perc $15>$ LAA $\%(-950 \mathrm{HU})$, as shown in Figure 5 and Table S3.

There was a significant difference between Model 4 and LAA\% (-950 HU) both in Group 1.1 and Group 1.2. The diagnostic value of the multivariable model in diagnosing persistent airflow limitation using different cut points is

shown in Table S4. Using $\mathrm{y} 4>-0.7$ as the criterion, the sensitivity was $63 \%$ and $61 \%$, and the specificity was $95 \%$ and $97 \%$ in Group 1.1 and Group 1.2, respectively.

\section{Discussion}

In this study, we analyzed patients' emphysema extent on CT scans and found its diagnostic value in identifying persistent airflow limitation. We also developed a diagnostic criterion for further verification.

Our results showed that almost all patients with high $\mathrm{FEV}_{1} / \mathrm{FVC}$ had low LAA\% and high Perc 15. These findings
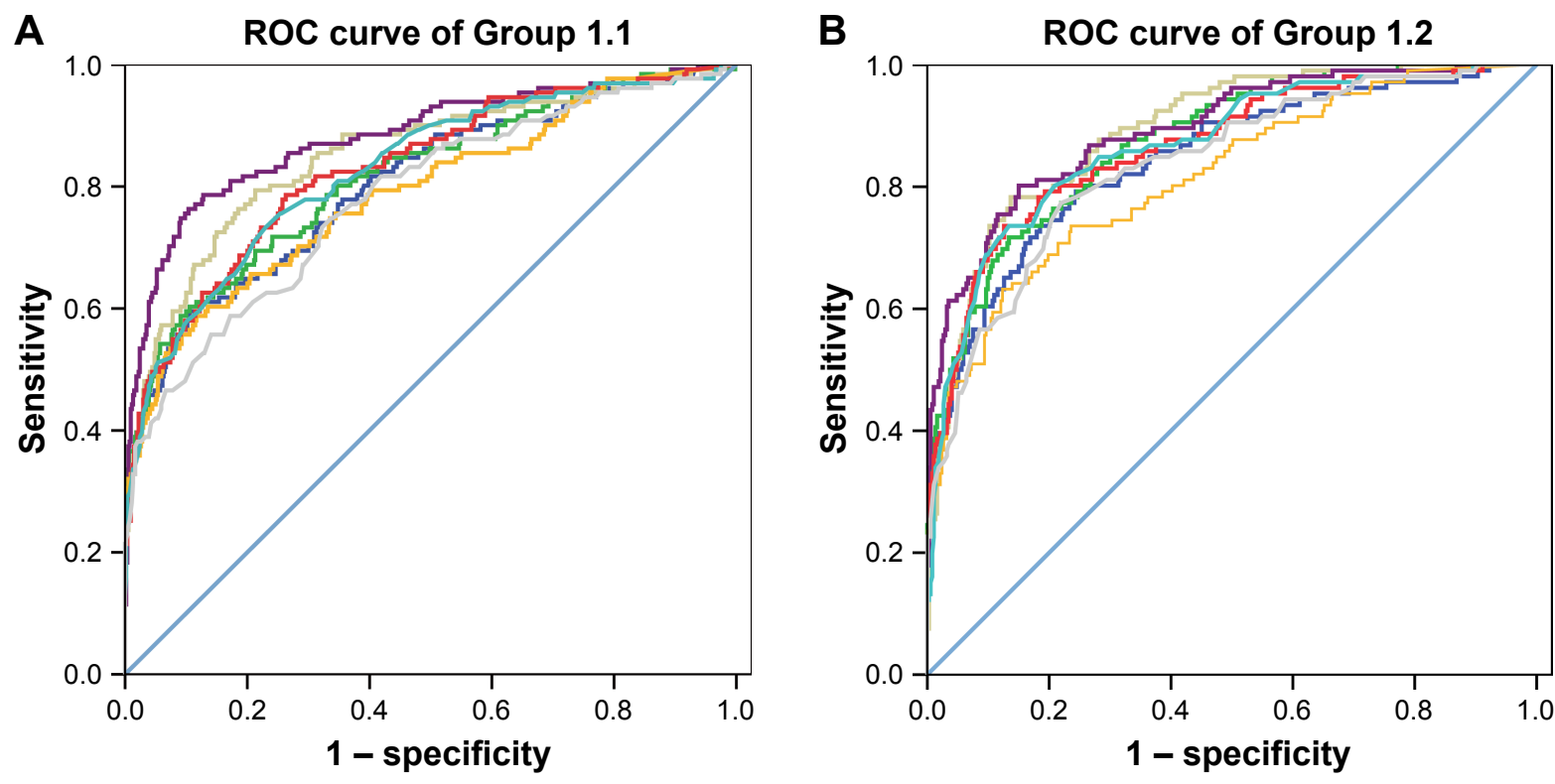

$\begin{array}{llll}\text { Source of the curve } & & \\ \text { Model } 1 & \text { Model } 2 & \text { Model 3 } & \text { Model } 4 \\ \text { LAA\% }(-950 \mathrm{HU}) & \text { LAA\% }(-930 \mathrm{HU}) & \text { Perc 3 } & \text { Perc } 15 \\ \text { Reference line } & & & \end{array}$

Figure 5 The ROC curve of emphysema indexes and predicting model in diagnosing consistent airflow limitation.

Notes: (A) Group I.I (derivation group); (B) Group I.2 (internal validation group). LAA\% (-950 HU) and LAA\% (-930 HU) indicate the percentage of the lung volume occupied by low attenuation areas using the thresholds of -950 and $-930 \mathrm{HU}$; Perc 3 and Perc 15 indicate percentile of the histogram of attenuation values.

Abbreviations: LAA\%, percentage of the lung volume occupied by low attenuation areas; Perc $n$, percentile of the histogram of attenuation values; ROC, receiver-operating characteristic. 
indicated that emphysema extent (ie, LAA\%, Perc n) on CT can be a highly specific index in diagnosing persistent airflow limitation. Moreover, Table 2 Part A reveals a positive likelihood ratio of 9.3 (Group 1.1) and 11.0 (Group 1.2) of $\mathrm{LAA} \%(-950 \mathrm{HU})>1.4 \%, 36.4$ (Group 1.1) and 28.3 (Group 1.2) of LAA\% ( $-950 \mathrm{HU})>3.0 \%$, and a negative likelihood ratio of 0.58 (Group 1.1) and 0.55 (Group 1.2) of LAA $\%(-950 \mathrm{HU})>1.4 \%$. It had been reported that a positive likelihood ratio $>10$ and a negative likelihood ratio $<0.1$ were regarded as the inclusion and exclusion criteria in most circumstances, respectively. ${ }^{16}$ Thus, we could conclude that a patient with an LAA $\%(-950 \mathrm{HU})>1.4 \%$ should be diagnosed with persistent airflow limitation, and the diagnosis was more accurate when LAA $\%(-950 \mathrm{HU})$ was $>3.0 \%$.

However, when LAA\% (-950 HU) was $<1.4 \%$, we still could not exclude the possibility of persistent airflow limitation. The sensitivity of the emphysema extent in persistent airflow limitation diagnosis was not as satisfactory as its specificity. In COPD, the narrow peripheral airways, which resulted from inflammation and the loss of alveolar elastic recoil force induced by emphysema (due to parenchymal destruction), could both lead to airflow limitation. ${ }^{17}$ Emphysema extent and airway measurements were independent predictive factors of persistent airflow limitation. ${ }^{18,19}$ Since COPD was a heterogenetic disease, ${ }^{20,21}$ patients with severe emphysema were supposed to suffer from persistent airflow limitation, while the absence of emphysema could not exclude the possibility of persistent airflow limitation.

It had been reported that LAA\% (-950 HU) and Perc 15 were widely accepted as the best indexes in CT emphysema evaluation. ${ }^{22}$ However, the selection of the optimal threshold was associated with the section thickness and reconstruction algorithm. Previous studies indicated that the LAA\% (-910 HU) correlated with the pathology grade of emphysema on CT scan with $1 \mathrm{~cm}$ thickness. ${ }^{23} \mathrm{LAA} \%$ (-950 HU) was the best index of macroscopic pathological emphysema extent on a $1 \mathrm{~mm}$ thick $\mathrm{CT}$ image, ${ }^{24}$ and on CT images reconstructed by $1.25,5.0$, and $10.0 \mathrm{~mm}$ section thickness and $20 \mathrm{~s}$ algorithm, the LAA\% (-960 HU), LAA\% (-970 HU), and Perc 1 had close correlation with the pathology emphysema extent. ${ }^{25}$ In our present study, the LAA\% with the threshold of $-930 \mathrm{HU}$ and Perc 3 had the highest AUC in identifying persistent airflow limitation. However, there was no significant difference in AUC between LAA\% with a threshold of $-930 \mathrm{HU}$ and LAA \% with a threshold of -950 HU, as well as between Perc 3 and Perc 15.
Patients with COPD often suffered from other lung diseases as well. We found that the coexistence of interstitial lung disease, pneumothorax, post-thoracic surgery, and bronchiectasis decreased the specificity of the emphysema extent. However, the coexistence of lung infiltration, and lung mass and nodule did not affect the specificity. This may be due to the honeycombing in interstitial lung disease, the area without lung texture in pneumothorax, the compensatory emphysema after pulmonary lobectomy, and the dilated airways in bronchiectasis.

In the analysis stratified by sex and age, the difference between the patients with and without persistent airflow limitation was more significant in males and patients aged 50-80 years. This was in line with the previous studies. It was reported that emphysema signs on CT were more common in men than women. ${ }^{26,27}$ Furthermore, Grydeland et al indicated that the emphysema extent on CT increased with age in both COPD and control groups. ${ }^{28}$ Therefore, the emphysema extent on CT may be affected by age and sex. When LAA\% (-950 $\mathrm{HU}$ ) or Perc 15 was regarded as the only emphysema index, the variables, including age, sex, and weight, were also independent predictors of persistent airflow limitation. However, if all the emphysema indexes were included, these population characteristics were no longer independent predictors.

There were several strengths for this study. First, this was a real-world study in China, with a relatively large sample size. Second, our results could be inferred to the patients coexistent with pneumonia, nodule, or mass. Third, the diagnostic values of emphysema extent and predictor model were validated in both internal validation and external validation groups. However, there were also several limitations in this study. First, some CT characteristics of COPD, including airway remodeling and air trapping, were not included in the present study. Second, the results of the present study were concluded from Chinese patients in a single-center study. Therefore, further researches in other areas and on other populations are still needed to investigate the proper cut points and diagnostic values. Third, COPD is a heterogeneous disease and persistent airflow limitation may be present without obvious emphysema; so, our results cannot reflect COPD patients with such characteristics. Fourth, it had been proved that CT with $<1 \mathrm{~mm}$ slice thickness was more sensitive ${ }^{29}$ and higherresolution $\mathrm{CT}$ provided higher diagnostic value. ${ }^{30}$ However, in our study, the emphysema extents were calculated from routing chest CT images (reconstructed by $5 \mathrm{~mm}$ thick sections and standard algorithms). Besides, various kernels for CT were used to evaluate the emphysema, which will affect the 
results in evaluating emphysema and bring natural limitation to the results. Finally, the medical history including the main symptoms and smoking status was not available, and thus, the diagnosis of COPD was inadequate. However, based on the present study, persistent airflow limitation can be diagnosed based on emphysema extent on CT. Thereafter, COPD can be diagnosed in the context of the medical history in clinics.

\section{Conclusion}

The emphysema extent on $\mathrm{CT}$ is a specific marker in the diagnosis of persistent airflow limitation, which can help with the diagnosis of COPD.

\section{Acknowledgments}

This study was supported by the Youth Project of Shanghai Municipal Commission of Health and Family Planning Research Project (No 20164Y0118), Research Foundation of Ruijin Hospital North, Shanghai Jiao Tong University School of Medicine (No 2015ZY04), Youth Talent Development Program by Ruijin Hospital North (No 2017RCPYB04) and Shanghai Key Discipline for Respiratory Diseases (2017ZZ02014). Ting Cheng and Yong Li share first authorship.

\section{Author contributions}

Conception and design of the research: Huan Ying Wan, Guo Chao Shi, Qi Jian Cheng, Qing Yun Li, Zi Lai Pan and Shao Guang Huang. Acquisition of data: Ting Cheng and Shuai Pang. Analysis and interpretation of data: Ting Cheng and Zi Lai Pan. Statistical analysis: Ting Cheng and Yong Li. Obtaining funding: Ting Cheng and Huan Ying Wan. Drafting the manuscript: Ting Cheng and Yong Li. Revision of manuscript for important intellectual content: Huan Ying Wan and Qi Jian Cheng. All authors contributed to data analysis, drafting and revising the article, gave final approval of the version to be published, and agree to be accountable for all aspects of the work.

\section{Disclosure}

The authors report no conflicts of interest in this work.

\section{References}

1. Rabe KF, Hurd S, Anzueto A, et al. Global strategy for the diagnosis, management, and prevention of chronic obstructive pulmonary disease NHLBI/WHO workshop report. Am J Respir Crit Care Med. 2014; 187(6):532-555.

2. Murray CJ, Lopez AD. Evidence-based health policy-lessons from the Global Burden of Disease Study. Science. 1996;274(5288):740-743.

3. Jonsson O, Gustafsson D. Spirometry and lung function in children with congenital deafness. Acta Paediatr. 2005;94(6):723-725.
4. Zebrowska A, Zwierzchowska A. Spirometric values and aerobic efficiency of children and adolescents with hearing loss. J Physiol Biochem. 2006;57(Suppl 4):443-447.

5. Kenny JE, Kuschner WG. Pneumothorax caused by aggressive use of an incentive spirometer in a patient with emphysema. Respir Care. 2013; 58(7): e77-e79.

6. Makris D, Bouros D. COPD exacerbation: lost in translation. BMC Pulm Med. 2008;9(1):1-3.

7. Parker CM, Voduc N, Aaron SD, Webb KA, O'Donnell DE. Physiological changes during symptom recovery from moderate exacerbations of COPD. Eur Respir J. 2005;26(3):420-428.

8. Hogg JC. Pathophysiology of airflow limitation in chronic obstructive pulmonary disease. Lancet. 2004;364(9435):709-721.

9. Hackx M, Bankier AA, Gevenois PA. Chronic obstructive pulmonary disease: CT quantification of airways disease. Radiology. 2012;265(1): 34-48.

10. Litmanovich D, Boiselle PM, Bankier AA. CT of pulmonary emphysemacurrent status, challenges, and future directions. Eur Radiol. 2009;19(3): $537-551$.

11. Mohamed Hoesein FA, de Jong PA, Lammers JW, et al. Computed tomography structural lung changes in discordant airflow limitation. PLoS One. 2013;8(6):e65177.

12. Haruna A, Muro S, Nakano Y, et al. CT scan findings of emphysema predict mortality in COPD. Chest. 2010;138(3):635-640.

13. Mets OM, Buckens CF, Zanen P, et al. Identification of chronic obstructive pulmonary disease in lung cancer screening computed tomographic scans. JAMA. 2011;306(16):1775-1781.

14. Li JS, Zhang HL, Bai YP, et al. Diagnostic value of computed tomography in chronic obstructive pulmonary disease: a systematic review and meta-analysis. J Chron Obstruct Pulmon Dis. 2012;9(5):563-570.

15. Mets OM, Schmidt M, Buckens CF, et al. Diagnosis of chronic obstructive pulmonary disease in lung cancer screening computed tomography scans: independent contribution of emphysema, air trapping and bronchial wall thickening. Respir Res. 2013;14(1):59-8.

16. Jaeschke R, Guyatt GH, Sackett DL. Users' guides to the medical literature. III. How to use an article about a diagnostic test. B. What are the results and will they help me in caring for my patients? The EvidenceBased Medicine Working Group. JAMA. 1994;271(9):703-707.

17. Rabe KF, Hurd S, Anzueto A, et al; Global Initiative for Chronic Obstructive Lung Disease. Global strategy for the diagnosis, management, and prevention of chronic obstructive pulmonary disease: GOLD executive summary. Am J Respir Crit Care Med. 2007;176(6):532-555.

18. Nakano Y, Muro S, Sakai H, et al. Computed tomographic measurements of airway dimensions and emphysema in smokers. Correlation with lung function. Am J Respir Crit Care Med. 2000;162(3 Pt 1):1102.

19. Kim WJ, Silverman EK, Hoffman E, et al. CT metrics of airway disease and emphysema in severe COPD. Chest. 2009;136(2):396-404.

20. Fujimoto K, Kitaguchi Y, Kubo K, Honda T. Clinical analysis of chronic obstructive pulmonary disease phenotypes classified using highresolution computed tomography. Respirology. 2006;11(6):731-740.

21. Kitaguchi Y, Fujimoto K, Kubo K, Honda T. Characteristics of COPD phenotypes classified according to the findings of HRCT. Respir Med. 2006;100(10):1742-1752.

22. Wang Z, Gu S, Leader JK, et al. Optimal threshold in CT quantification of emphysema. Eur Radiol. 2013;23(4):975-984.

23. Müller NL, Staples CA, Miller RR, Abboud RT. "Density mask". An objective method to quantitate emphysema using computed tomography. Chest. 1988;94(4):782-787.

24. Gevenois PA, de Maertelaer V, De Vuyst P, et al. Comparison of computed density and macroscopic morphometry in pulmonary emphysema. Am J Respir Crit Care Med. 1995;152:653-657.

25. Madani A, Zanen J, de Maertelaer V, Gevenois PA. Pulmonary emphysema: objective quantification at multi-detector row CT-comparison with macroscopic and microscopic morphometry. Radiology. 2006;238(3): 1036-1043. 
26. Dransfield MT, Washko GR, Foreman MG, Estepar RS, Reilly J, Bailey WC. Gender differences in the severity of CT emphysema in COPD. Chest. 2007;132(2):464-470.

27. Hardin M, Foreman M, Dransfield MT, et al. Sex-specific features of emphysema among current and former smokers with COPD. Eur Respir J. 2016;47(1):104-112.

28. Grydeland TB, Dirksen A, Coxson HO, et al. Quantitative computed tomography: emphysema and airway wall thickness by sex, age and smoking. Eur Respir J. 2009;34(4):858-865.
29. Smith BM, Austin JHM, Newell JD, D'Souza BM, Rozenshtein A. Pulmonary emphysema subtypes on computed tomography in smokers. Am J Med. 2014;127(1):94.e7-e23.

30. Nishimura K, Murata K, Yamagishi M, et al. Comparison of different computed tomography scanning methods for quantifying emphysema. J Thorac Imaging. 1998;13(3):193-198.

\section{Publish your work in this journal}

The International Journal of COPD is an international, peer-reviewed journal of therapeutics and pharmacology focusing on concise rapid reporting of clinical studies and reviews in COPD. Special focus is given to the pathophysiological processes underlying the disease, intervention programs, patient focused education, and self management protocols.
Dovepress

This journal is indexed on PubMed Central, MedLine and CAS. The manuscript management system is completely online and includes a very quick and fair peer-review system, which is all easy to use. Visit $\mathrm{http} / / / \mathrm{www}$.dovepress.com/testimonials.php to read real quotes from published authors. 